\title{
The effect of growth regulators on the regeneration ability of flax (Linum usitatissimum L.) hypocotyl explants in in vitro culture
}

\author{
Jowita JANOWICZ ${ }^{*}$, JANETTA NiEmanN, ANDRZEJ WOJCIECHOWSKI \\ Department of Genetics and Plant Breeding, Poznań University of Life Sciences, Poznań, Poland \\ *Corresponding author: jowita6@interia.pl
}

\begin{abstract}
The aim of the present study is to determine the influence of different concentrations of growth regulators on the hypocotyl explants regeneration abilities of flax cultivars (Linum usitatissimum L.). Plant material used in the study was obtained from two flax cultivars: Modran and Selena. Hypocotyl explants were obtained from 6-dayold seedlings and were subsequently placed on basal MS (Murashige and Skoog 1962) medium and MS medium supplemented with 6-benzylaminopurine (BAP) or naftalene acetic acid (NAA). Final evaluation of the callus, the shoot and the root formation of the explants was performed 28 days after the experimental setup. The highest regeneration effectiveness was observed on the media supplemented with $1 \mathrm{mg} / \mathrm{l} \mathrm{BAP}$.
\end{abstract}

Key words: flax, regeneration, in vitro cultures, hypocotyl, BAP, NAA

\section{Abbreviations}

MS - Murashige and Skoog (1962) medium

BAP - benzylaminopurine

2iP - 2-isopentenyladenine

\section{Introduction}

Linum genus, belonging to the Linaceae botanical family, consists of approximately 300 species, most of which are wild, a few are grown as ornamental plants, some fibrous forms have become of local significance; however, only one species of flax i.e. L. usitatissimum is commonly cultivated. Flax was, and still is, very valuable and economically important plant. Moreover, every part of the plant is potentially useful: the stem is the source of fibers and shives, while the seed capsules provide seeds and chaffs. As far as the textile industry is concerned, flax is the only source of cellulosic fiber in the countries with temperate climate. Furthermore, it can be successfully applied in many branches of construction industry, and used as a fodder component in animal feed. Linseed, on the other hand, is a component used in the oil, pharmaceutical, cosmetic and food industry (Duguid, 2009; Cullis, 2011).

Flax is a plant species commonly used in biotechnology, and its exploration frequently involves biochemical and in vitro plant regeneration techniques. In vitro regeneration of flax has been conducted for many years,

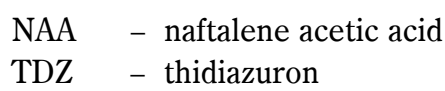

and in many laboratories different types of explants have been used for effective regeneration of this species (Rybczyński, 1975; Chlyach et. al., 1980; Pretova and Williams, 1986; Basiran et al., 1987; Ling and Binding, 1987, 1992; Zhan et al., 1988, 1989a). In vitro regeneration technique is also conducted to obtain transgenic plants with favorably modified features. Such modifications may be effectively introduced into this species via genetic engineering. The above-mentioned modified features concern both, the quality of fiber and the composition of flax seeds (Wróbel et al., 2004; Wróbel-Kwiatkowska et al., 2009; Miśta et al., 2011).

It has been previously found that regeneration of flax plants is more likely to succeed from hypocotyl segments, and relatively harder from leaf explants, the callus or the protoplasts fusion (Yilidiz and Özgen, 2004). Despite the fact that in vitro cultures of flax have been studied from many years, literature regarding the control of the efficiency of embryo regeneration and organogenesis are still insufficient (Burbulis et al., 2005).

In vitro regeneration depends on various factors, the alteration of which may improve culture efficiency. 
Not only the change of media and use of various culture conditions, but also the choice of the tissue source for the explant, provides an opportunity to gain the optimal regenerating configuration. Therefore, in the present study, the influence of five different concentrations of 6-benzylaminopurine (BAP) and naftalene acetic acid (NAA) on the regeneration abilities of hypocotyl explants of two flax cultivars (Linum usitatissimum L.) was determined.

\section{Material and methods}

Plant material used in the research consisted of two flax cultivars: Modran and Selena, from which 6-day-old sterile seedlings and hypocotyl explants were obtained. Sterile seedlings were produced from seeds sterilized in a commercial bleach (Ace) diluted with distilled water (ratio 1:5, v/v) for 5 minutes, and subsequently rinsed three times with sterile distilled water. Sterile seeds were placed in Petri dishes and incubated under culture room conditions: 16 hours light $/ 8$ hours dark at $26^{\circ} \mathrm{C}$. After 6 days, hypocotyl explants were excised from the seedlings and placed on MS basal medium (Murashige and Skoog, 1962) and MS medium supplemented with different concentrations of BAP or NAA. Both regulators, BAP and NAA, were applied in the same concentrations: $0.2 ; 0.5 ; 1.0 ; 1.5$ and $2.0 \mathrm{mg} / \mathrm{l}$. In three Petri dishes, containing the specific medium, three explants of particular cultivar were placed. The experiment was carried out in three replications for each cultivar. The definitive evaluation of callus, shoot and root regeneration was performed 28 days after the experiment was set up. The data were analyzed by multiple range Duncan test $(\alpha=0.05)$.

\section{Results and discussion}

Hypocotyl explants of two investigated cultivars formed shoots on MS control medium and on media supplemented with growth regulators by direct organogenesis. Callus was formed on explants only in places where the tissue was injured. None of the explants formed roots. Shoot regeneration effectiveness, defined by the percentage of hypocotyls explants forming shoots, is presented in Table 1.

Both the analyzed cultivars displayed different regeneration abilities. The percentage of explants forming shoots and the number of shoots formed by one explant
Table 1. The percentage of flax (Linum usitatissimum L.) cultivars hypocotyl explants forming shoots on control MS medium and MS medium supplemented with different concentrations of BAP and NAA

\begin{tabular}{|c|c|c|}
\hline \multirow{3}{*}{$\begin{array}{c}\text { Growth } \\
\text { regulators } \\
\text { concentration } \\
{[\mathrm{mg} / \mathrm{l}]}\end{array}$} & \multicolumn{2}{|c|}{ Cultivar } \\
\hline & \multicolumn{2}{|c|}{ mean $\%$ of explants forming shoots } \\
\hline & Modran & Selena \\
\hline MS & $74.1^{\mathrm{cd}^{*}}$ & $55.6^{\mathrm{gh}}$ \\
\hline $\mathrm{MS}+0.2 \mathrm{BAP}$ & $77.8^{\mathrm{bc}}$ & $56.9^{\text {gh }}$ \\
\hline $\mathrm{MS}+0.5 \mathrm{BAP}$ & $81.5^{\mathrm{b}}$ & $59.3^{\text {fg }}$ \\
\hline $\mathrm{MS}+1.0 \mathrm{BAP}$ & $92.6^{\mathrm{a}}$ & $70.4^{\mathrm{de}}$ \\
\hline $\mathrm{MS}+1.5 \mathrm{BAP}$ & $88.9^{\mathrm{a}}$ & $66.7^{\text {ef }}$ \\
\hline $\mathrm{MS}+2.0 \mathrm{BAP}$ & $75.2^{\mathrm{cd}}$ & $63.0^{\mathrm{f}}$ \\
\hline $\mathrm{MS}+0.2 \mathrm{NAA}$ & $63.0^{\mathrm{f}}$ & $51.9^{\text {hi }}$ \\
\hline $\mathrm{MS}+0.5 \mathrm{NAA}$ & $55.6^{\text {gh }}$ & $48.1^{\mathrm{ij}}$ \\
\hline $\mathrm{MS}+1.0 \mathrm{NAA}$ & $51.9^{\text {hi }}$ & $48.1^{\mathrm{ij}}$ \\
\hline $\mathrm{MS}+1.5 \mathrm{NAA}$ & $48.1^{\mathrm{i}}$ & $44.4^{\mathrm{j}}$ \\
\hline $\mathrm{MS}+2.0 \mathrm{NAA}$ & $74.1^{\mathrm{cd}}$ & 37.0 \\
\hline
\end{tabular}

* Means followed by the same letter do not differ significantly at $\alpha=0.05$

were modified by growth regulators added to the medium as described below.

On the control MS medium, "Modran" and "Selena" hypocotyl explants formed shoots with the frequency of $74.1 \%$ and $55.6 \%$, respectively. An addition of BAP into the medium gradually increased the number of hypocotyls forming shoots. Even a low concentration of BAP in the media $(0.2 \mathrm{mg} / \mathrm{l})$, stimulated regeneration in both cultivars. With an increase in the concentration of this growth regulator in the medium (but only to the certain level), a percentage increase in the explants forming shoots was observed. On the other hand, at concentration above $1.0 \mathrm{mg} / \mathrm{l} \mathrm{BAP}$ in the medium, a decrease in the number of explants forming shoots appeared. It was also noted that despite the decrease in the regeneration effectiveness, at higher BAP concentrations, the percentage of explants forming shoots was still higher than on the control MS. The best medium for both cultivars appeared to be the one supplemented with $1 \mathrm{mg} / \mathrm{lBAP}$. As far as this concentration is concerned, the effectiveness in both cultivars, "Modran" and "Selena" valued 92.6\% and $70.4 \%$, respectively.

Another growth regulator tested in this study was NAA, which generally decreased the ability of forming 


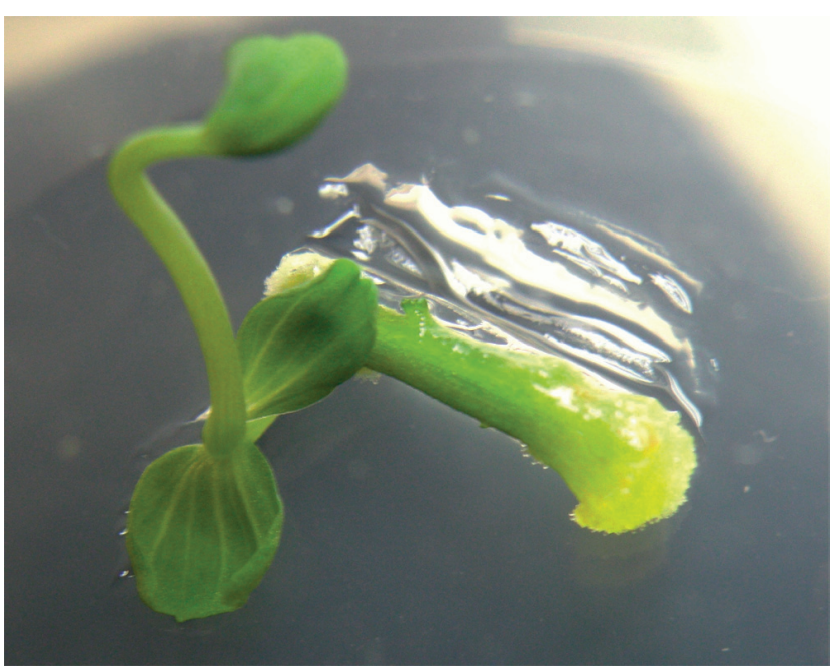

Fig. 1. Modran flax (Linum usitatissimum L.) cultivar hypocotyl explant forming shoots on the control MS medium

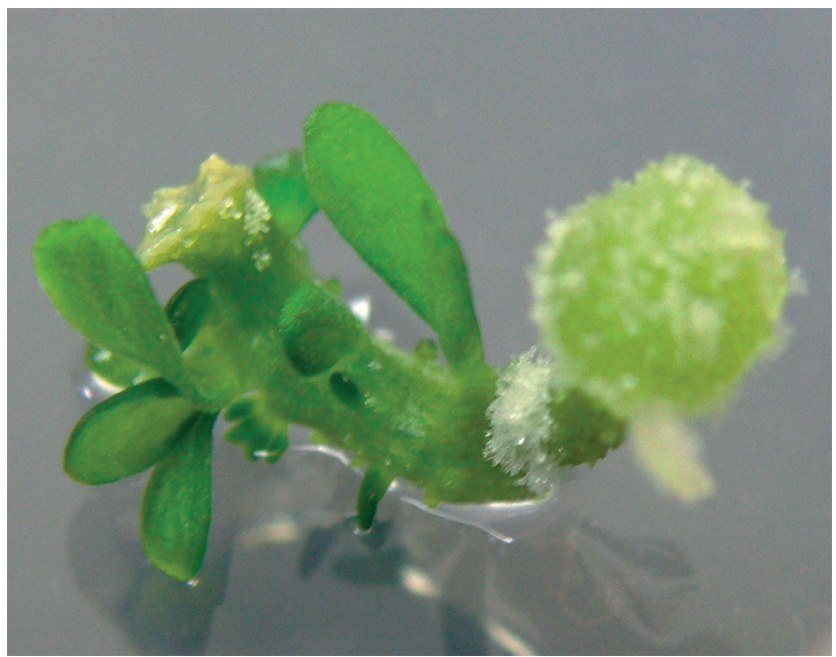

Fig. 2. Modran flax (Linum usitatissimum L.) cultivar hypocotyl explant forming shoots on MS medium supplemented with $1.0 \mathrm{mg} \mathrm{mg} / \mathrm{l} \mathrm{BAP}$

shoots by hypocotyl explants. Even small amounts of NAA added to the medium prompted the negative effect in this respect. Eventually, for $2 \mathrm{mg} / \mathrm{lNAA}$ concentration in the medium, the regeneration abilities valued $48.1 \%$ for Modran, and 37.0\% for Selena cultivar. Moreover, an increased number of withered hypocotyl explants was observed on the medium supplemented with NAA.

Furthermore, there were differences in the number of shoots formed by one explant (data are not presented in the table because in most cases the same values were observed). In comparison to the control media, on which hypocotyls formed on an average 1-3 shoots (Fig. 1), on the media supplemented with BAP or NAA, the number of shoots was higher and ranged from 5 to 8 shoots per explant (Fig. 2).

The plant growth regulators applied in this experiment had a significant influence on the successful in vitro culture with each phytohormone having a specific influence on the plant development. It has been known for a long time that by the appropriate choice of substances (e.g. hormones) and their concentrations, the growth of cells and organs for in vitro cultures can be easily controlled (Pierik, 1987). However, the available literature demonstrates that flax appears to be very prone to any modifications in the media, including the addition of various growth regulators at different concentrations. Not only the growth regulators presented in this study are commonly used, there were also others, such as e.g. TDZ or 2iP (Yildiz and Özgen, 2006; Burbulis et al., 2009). According to several studies, BAP is one of the most effective hormones that may be used to improve the regeneration abilities of flax under in vitro conditions (Zhan et al., 1989b; Janowicz and Wojciechowski, 2009). In our experiments, an addition of BAP to the medium also increased the number of explants forming shoots, for both cultivars. Similarly, other sources show that $1 \mathrm{mg} / \mathrm{l} \mathrm{BAP}$ enrichment is the most effective concentration of the regulator for this species (Burbulis et al., 2007). On the other hand, an addition of NAA does not improve the explants regeneration abilities. In addition, NAA decreases this ability and lowers the effectiveness of shoot formation, in comparison to the control (Belonogova and Raldugina, 2006). According to literature, an addition of $1 \mathrm{mg} / 1 \mathrm{BAP}$ and $0.02 \mathrm{mg} / 1 \mathrm{NAA}$ is the best combination to stimulate the regeneration of flax under in vitro conditions (Dong and McHughen, 1993). In the present study, no attempts to combine those growth regulators were made, although the idea seems worthwhile exploring further in the future.

\section{References}

Basiran N., Armitage P., Scott R.J., Draper J. (1987) Genetic transformation of flax (Linum usitatissimum) by Agrobacterium tumefaciens: regeneration of transformed shoots via a callus phase. Plant Cell Rep. 6(5): 396-399.

Belongova M.A., Raldugina G.N. (2006) Shoot regeneration from cotyledon explants of fibre flax (Linum usitatissimum) and their subsequent rooting. Russian J. Plant Physiol. 4: 501-506. 
Burbulis N., Blinstrubiene A., Venskutoniene E., Katauskyte L. (2005) Organogenesis in callus cultures of Linum usitatissimum L. Acta Univ. Latv. Univ. Biol. 691: 129-135.

Burbulis N., Blinstrubiene A., Kupriene R., Sliesaravicius A., Venskutoniene E. (2007) Optimization of linseed flax ( $\mathrm{Li}$ num usitatissimum L.) in vitro cultures. ZemdirbysteAgricult. 94(4): 120-128.

Burbulis N., Blinstrubiene A., Kupriene R. (2009) Regeneration of adventitious shoots of linseed (Linum usitatissimum L.) from hypocotyls explants. Zemdirbyste-Agricult. 96(3): 168-175.

Chlyah H., Sqalli-Khalil M., Chlyah A. (1980) Dimorphism in bud regeneration in flax (Linum usitatissimum). Can. J. Bot. 58(6): 637-641.

Cullis C. (2011) Linum. In: Wild crop relatives: genomic and breeding resources, oilseeds, ed. Kole C, Springer-Verlag, Heidelberg-Berlin, pp. 177-189.

Dong J., McHughen A. (1993) An improved procedure for production of transgenic flax plants using Agrobacterium tumefaciens. Plant Sci. 88: 61-71.

Duguid S.D. (2009) Flax. In: Oil crops, handbook of plant breeding 4, ed. Vollmann J., Rajcan I., Springer Science Business Media, New York, pp. 233-254.

Janowicz J., Wojciechowski A. (2009) The evaluation of regeneration ability of two flax (Linum usitatissimum L.) cultivars in in vitro culture. Oilseed Crops 30(1): 35-50.

Ling H.Q., Binding H. (1987) Plant regeneration from protoplasts in Linum. Plant Breeding 98: 312-317.

Ling H.Q., Binding H. (1992) Improvement of plant regeneration from Linum protoplasts by the induction of somatic embryogenesis. J. Plant Physiol. 139(4): 422-426.

Miśta D., Króliczewska B., Zawadzki W., Pecka E., Steininger M., Hull S., Żuk M., Szopa J. (2011) The effect of Linola and W92/72 transgenic flax seeds on the rabbit caecal fermentation - in vitro study. Pol. J. Vet. Sci. 14(4): 557-564.
Murashige T., Skoog F. (1962) A revised medium for rapid growth and bio-assays with tobacco tissue cultures. Physiol. Plant. 15: 473-497.

Pierik R.L.M. (1987) In vitro culture of higher plants. Martinus Nijhoff Publisher, Dordrecht.

Pretova A., Williams E.G. (1986) Direct somatic embryogenesis from immature zygotic embryos of flax (Linum usitatissimum L.). J. Plant Physiol. 126: 155-161.

Rybczyński J.J. (1975) Callus formation and organogenesis of mature cotyledons of Linum usitatissimum var. Szokijskij in vitro culture. Genet. Polon. 16: 161-166.

Wróbel M., Zebrowski J., Szopa J. (2004) Polyhydroxybutyrate synthesis in transgenic flax. J. Biotech. 107(1): 41-54.

Wróbel-Kwiatkowska M., Żuk M., Szopa J., Dymińska L., Mączka M., Hanuza J. (2009) Poly-3-hydroxy butyric acid interaction with the transgenic flax fibers: FT-IR and Raman spectra of the composite extracted from a GM flax. Spectrochimi. Acta Part A 73: 286-294.

Yildiz M., Özgen M. (2004) The effect of a submersion pretreatment on in vitro explant growth and shoot regeneration from hypocotyls of flax (Linum usitatissimum L.). Plant Cell Tissue Organ Cult. 77: 111-115.

Yildiz M., Özgen M. (2006) A comparison of growth regulators for adventitious shoot regeneration from hypocotyls of flax (Linum usitatissimum L.). J. Food Agricult. Environ. 4: $171-174$.

Zhan X.-C., Jones D.A., Keer A. (1988) Regeneration of flax plants transformed by Agrobacterium rhizogenes. Plant Mol. Biol. 11(5): 551-559.

Zhan X.-C., Jones D.A., Keer A. (1989a) Regeneration of shoots on root explants of flax. Ann. Bot. 63(2): 297-299.

Zhan X.-C., Jones D.A., Keer A. (1989b) In vitro plantlet formation in Linum marginale from cotyledons, hypocotyls, leaves, roots and protoplasts. Aust. J. Plant Physiol. 16: 315-320. 